ELECTRONICS

\section{Fluid-based sensor bends and twists}

Electronic sensors made using liquids can outperform other flexible devices that have solid components.

Most sensors rely on solid metals that form junctions. To render such devices flexible, Ali Javey of the University of California, Berkeley, and his colleagues developed a way to make a junction between two different fluids that does not allow them to mix.

For the junction, the team fabricated a series of microchannels, each about 30 micrometres wide, which are designed to let in only one of the fluids - an ionic liquid. The other fluid, the commercial liquid metal Galinstan, has too much surface tension to enter the channels.

The sensors could detect humidity, oxygen and temperature; the temperature sensor was 17-46 times more sensitive than flexible alternatives made with solid components. The device could be useful in prostheses, robotics and smart wallpapers, the authors say.

Nature Commun. 5, 5032 (2014)

\section{GENOMICS}

\section{Hundreds of genes for height}

One of the largest-ever genome-wide association studies has identified 697 genetic variants for human height - several hundred more than a previous, smaller study.

Peter Visscher of the University of Queensland in Brisbane, Australia, and a team of hundreds of scientists analysed the combined results

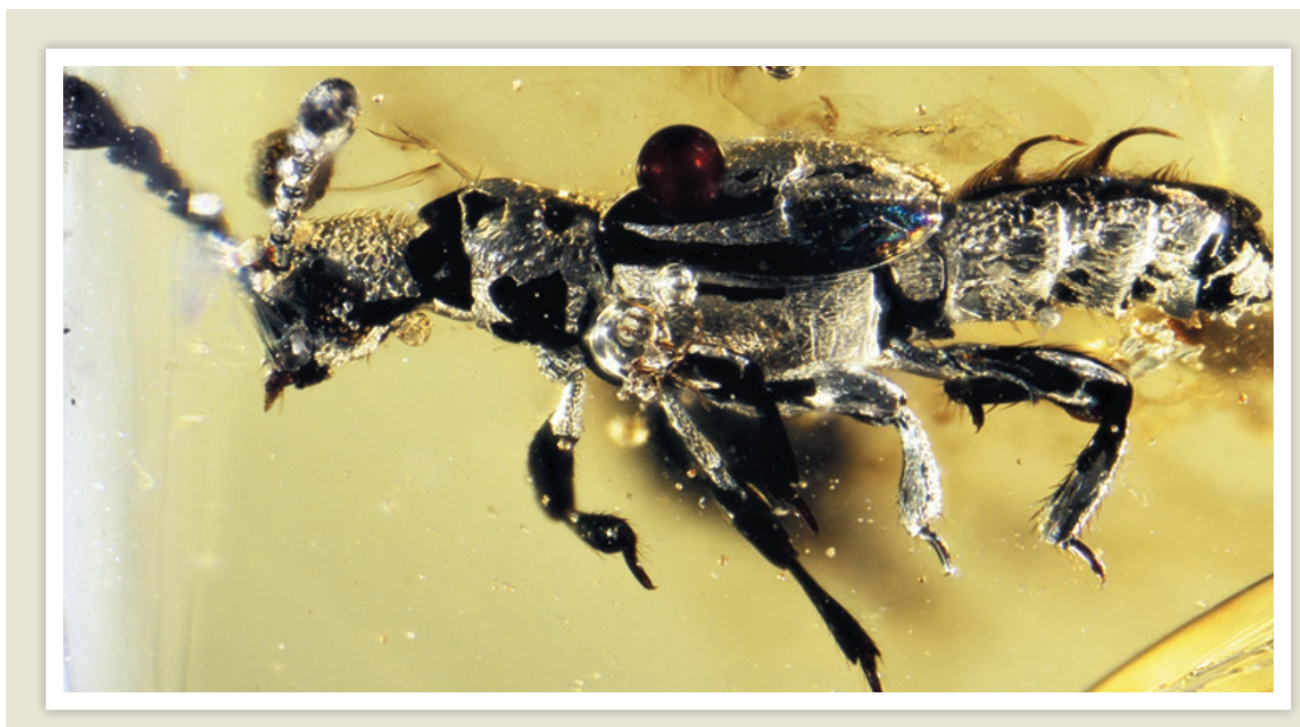

EVOLUTION

\title{
Oldest ant lover found entombed
}

Insects that embed themselves in ant colonies have existed for nearly as long as their hosts, and some have evolved rapidly, probably in response to ant diversification.

Joseph Parker at Columbia University and David Grimaldi from the American Museum of Natural History, both in New York, conclude that a 52-million-year-old beetle found entombed in amber (pictured) is the earliest known example of a myrmecophile - species that depend on ants for their survival. The newly identified species, Protoclaviger trichodens, is an extinct ancestor of contemporary rove beetles and has features such as hairs to deliver tasty secretions to worker ants. It existed just as ant populations were starting to rise in tropical rainforests.

In another myrmecophile study, Wendy Moore and James Robertson at the University of Arizona in Tucson used DNA sequences to examine the evolutionary relationships of antnest beetles (Paussus spp). They found that the beetles are some of the fastest evolving animals on Earth. For example, the common ancestor of the 86 species that are native to Madagascar existed just 2.6 million years ago.

Curr. Biol. http://doi.org/v6q; http://doi.org/v6r (2014) of 79 genome-wide association studies, encompassing 253,288 people, and found that the common gene variants account for $16 \%$ of the genetic contribution to height. Many of the variants lie near genes in biochemical pathways associated with skeletal growth, and others were linked to genes that were not previously thought to be growth-related.

The authors suggest that tens of thousands of common genetic variants together influence height, and that bigger genome-wide association studies including hundreds of thousands of people will continue to provide useful biological information. Nature Genet. http://doi.org/v6k (2014)

CLIMATE CHANGE

\section{Ocean warming underestimated}

Recent estimates of global temperature rises in the upper ocean may have been too low.

Oceans absorb the majority of the heat resulting from global warming. Paul Durack of the Lawrence Livermore National Laboratory in California and his colleagues used a range of climate models and satellite observations to reassess observed changes in ocean warming between 1970 and 2004. They concluded that upper-ocean warming has been underestimated by as much as $58 \%$, mainly because of sparse data from oceans in the Southern Hemisphere.

A separate study by William Llovel and his colleagues at NASA's Jet Propulsion Laboratory in Pasadena, California, showed that the 